To Cite: Lin, A. M. Y., \& Tong, A. (2007). Text-messaging cultures of college girls in Hong Kong: SMS as resources for achieving intimacy and gift-exchange with multiple functions. Continuum: Journal of Media and

Cultural Studies, 21 (2), 303-315

\title{
Text-messaging Cultures of College Girls in Hong Kong: SMS as Resources for Achieving Intimacy and Gift-Exchange with Multiple Functions
}

\section{Introduction}

Mobile text messaging, or variously known as SMS (short message service), text messaging, mobile e-mail, or texting, has become a common means of keeping in constant touch, especially among young people in many parts of the world today. The research literature abounds with studies on the social, cultural, linguistic and communicative aspects of mobile text messaging in different sociocultural contexts in the world. However, almost all of these studies have been conducted outside of Hong Kong. Below we shall provide a preliminary literature review of earlier studies related to SMS. Then we shall present our pilot qualitative study. In the findings and discussion section, we shall interpret the findings in light of the relevant research literature.

\section{Linguistic Analysis of SMS Messages}

A small but significant set of studies concentrates on the linguistic, semiotic and sociolinguistic analysis of mobile text messages and shows how written language is creatively and effectively adapted to suit the parameters of the new medium (e.g., limited message size, text input technique) for a wide variety of communicative functions. They generally show that contrary to some popular disparaging beliefs that SMS language is 'broken language' and might harm students' literacy skills (e.g., Allison, 2001; Tweedle, 2003; Wilson, 2003), text messaging language use is actually creative and well-suited to the particular mode of SMS communication (e.g., Hard af Sergerstad, 2003). SMS texts are found to attempt maximum economy in script resulting in cryptic, semi-coded messages with hybridized orthography and creative use of various non-letter characters (e.g., numerals, emoticons) in spelling/writing (Pietrini, 2001; Galan Rodriguez, 2001; Almela Perez, 2001). SMS language should therefore be seen as a new, creative, hybridized variety of literacy in its own right rather than a 'broken form' of a traditional print language. Mobile textuality involves a radical fragmentation and unpredictable seriality of text lexia (Goggin, 2004); it is a 
new form of literacy particularly suited to the special features of the new communication medium rather than a degenerated form of print literacy.

\section{Analysis of the Social Impact of New Mobile Communication Technologies}

A much larger body of works focuses on the impact of new mobile communication technologies (including both synchronous technology-mobile phone and asynchronous communication technology-SMS) on society and modernity, and the role it plays in changing social relations and social interactional practices, especially among young people.

In contrast to the general celebratory optimistic tone of the promotional/advertising discourses of mobile communication companies (e.g., 'ever closer human relationships', 'closer family ties', 'instant and constant touch'), cultural studies researchers generally tend to stay with a much more cautious and perhaps even pessimistic tone in their theorizing of the social and cultural implications of new mobile communication technologies. For instance, in an essay on 'mobile privatization' Raymond Williams (1983) wrote:

There is then a unique modern condition, which I defined in an earlier book (Television: technology and cultural form, 1974) as 'mobile privatization'. It is an ugly phrase for an unprecedented condition. What it means is that at most active social levels people are increasingly living as private small-family units, or, disrupting even that, as private and deliberately self-enclosed individuals, while at the same time there is a quite unprecedented mobility of such restricted privacies. (p. 129)

For Williams the new mobile technologies (mainly referring to the walkman at that time) only serve to further aggravate the modern human condition of 'mobile-privatized social relations'. To illustrate what he meant, Williams used the visual image of car traffic: people insulated in their own moving (mobile) 'shells' (cars) communicate only with their own social networks of acquaintances (people traveling in the private car) in their own mobile 'shells' without any concern for other fellow human beings in other 'shells'. There is an old Chinese saying which captures well this concern of Williams about late modernity: 'Each family only sweeps the snow on their own doorway and nobody cares about the frost on other people's roofs'. The modern and late modern condition of a diminishing sense of community and the public sphere, and the increasing insulation of people into their own small 'shells' (or insulated units: houses, apartments, private cars, or nowadays private mobile phone networks) seems to be a concern that is aggravated further by 
new mobile communication technologies. People talk of 'detached presence'-i.e., one can insulate oneself from other people in the surroundings and withdraw into one's own private world by immersing oneself in the walkman world, or by talking or text-messaging via the mobile phone.

This cautious note is echoed in a recent article on social theory in the wireless world by Cooper (2001). Quoting Heidegger's notion of modern technology as something which 'enframes' or converts the world into a resource to be utilized, Cooper concluded that perpetual availability is both an advantage and disadvantage-'You can run but you can't hide': the new mobile communication technologies convert people into resources - to be constantly on call/in touch is to be constantly instrumentalized by others (e.g., employees have no excuse of not answering mobile phone calls or not responding to text messages from their boss).

This cautious note is also found in youth mobile communication studies: young people's constant use of mobile communication (e.g., mobile phoning or text-messaging) can be seen as a symptom of a general loss of human connectivity in the modern condition. On this Lobet-Maris (2003) made an insightful observation:

For beneath the surface of this mobile phone usage there is first and foremost a rather desperate search for social existence, for a social connection in a world that appears less and less communicative to youth. For such reasons, as the research shows, about half of young people apparently would be willing to receive wireless advertising messages. These are all indications... of the need for communication that some young people feel today. The rise in importance of mobile phones and pagers among young people is perhaps the most convincing sign of a 'disconnected' society. (p. 91)

Still others in Finland are concerned about their traditional speech culture being increasingly replaced by a new 'shallow' mobile communication culture. For instance, Puro (2002) expressed worries that traditional Finnish speech culture which values silence and direct, informative, matter-of-fact talk in phone conversations is now being replaced by new speech cultural practices that characterize mobile phone usage: shallow, small talk. Puro lamented 'nokialization' and warned of the gradual loss of the traditional Finnish way of life.

Cultural studies researchers might be cautious of Puro's (2002) seeming construction of a static, binary, 2-culture theory: old and new cultures each with fixed boundaries, with new mobile communication technologies seen as bringing in the new culture 
(way of life) which replaces the old culture (way of life). Without falling into the trap of technological determinism, many mobile communication researchers have focused on the complex processes in which mobile communication technologies interact with existing sociocultural practices and on the new technologies as affording resources for change in social interactional practices to gradually develop (Katz \& Aakhus, 2002). An important force driving these processes might be the human need for management of social roles, social relations, individual and group identities, images and commitments (Goffman, 1959). Recent research studies on mobile communication have examined how SMS can afford a sense of intimacy between friends as well as between strangers.

\section{SMS as a Resource to Achieve a (Quasi-)Sense of Intimacy in Social \\ Relationships}

It seems that mobile communication technology can provide new affording resources to maintain existing social relationships in expanded spatio-temporal contexts (Pertierra et al, 2002). The virtual presence (or 'absent presence') of 'persons elsewhere' through mobile communication facilitates networking, deeper relationships or simply increased contact (Gergen, 2002; Harper, 2003). People who are physically far away can be brought into immediate cyber presence. This feature of mobile communication is especially appealing to youth, as they consider constant social contact and a sense of co-presence very important. Ling (2004) describes mobile phone as a device providing 'anytime-anywhere-for-whatever-reason type of access' to other members of one's peer group, and this can produce tightly bonded social networks among youths.

In particular, text messaging is more individualized than traditional telephony, as we expect that the message will reach a specific person directly, regardless of where the person is at that moment (Ling, 2004). Ito and Okabe (2005) found that many messages were exchanged for the purpose of maintaining lightweight contact and co-presence rather than exchange of real information. Texting thus plays an important role in maintaining regular touch between friends and intimates. This mode of text sharing is called 'ambient virtual co-presence'. Hjorth (2005) also examines the generic functions of SMS and its contribution to the perpetual encircling of place, locality and practices of co-presence. It seems that text messaging has created new kinds of modalities for co-presence and communication, which contributes to a sense of virtual intimacy. 
The Longman Dictionary (1988) defines the word 'intimacy' as referring to 'the state of being intimate', 'close friendship', 'the act of sex', as well as 'speech or an action such as is permitted only between people who know each other very well'. It thus includes both friendship and romance relationship. As Ito (2002) argues in the context of Tokyo, and Yoon (2003) in the context of Seoul, mobile phone practices are contingent upon the agencies of the local and contribute to maintaining intimacy among friends. On the other hand, some studies also discuss the sense of intimacy between strangers brought about by text exchanges (Ling and Yittri, 2002; Grinter and Eldridge, 2001; Ling, 2000). SMS can spark instant romantic relationships and give a (quasi-)sense of immediate intimacy (Prøitz, 2005).

In the Philippines, a Southeast Asian society regarded as the texting capital of the world, text messaging provides young people with an avenue to express their curiosities and desires, especially those about erotic love (Ellwood-Clayton, 2006). Pierterra $(2004,2006)$ suggests that mobile technologically mediated relationships blur the lines between the real, the surreal and the fantastic, and it opens up possibilities for intimate relationships even between strangers.

\section{SMS as a Resource to Achieve Freedom from Adult Surveillance}

Ito and Daisuke (2003) studied the kind of social structural factors that relate to unique patterns of mobile phone usage, particularly text messaging of teenagers in Japan. It is found that Japanese teens' penchant for text messaging is an outcome of a wide range of factors. These include the unique expressive functions and styles of this form of communication but also most importantly factors that relate to adults' control and surveillance in particular places. Japanese youth, particularly high school students, move between the places of home, school, and urban space that are all subject to a high degree of regulation and surveillance by adults. Even public urban space is highly regulated by certain codes of social conduct and a whole range of regulatory efforts that limit or constrain young people's ways of communication on public transport. Youth peer groups and couples lack ownership and control of place and couples and friends have few opportunities for private conversation.

Mobile text-messaging has thus fulfilled an important function which provides a sense of co-presence for young people who lack the means to share some private physical space free from adults' surveillance. The SMS communication technology thus provides an infrastructure or a tool for young Japanese teens to open up a safe private communication and sociality space that escapes the traditional disciplining and surveillance structures and apparatus controlled by adults. Given the relative cultural 
proximity between Japanese sociocultural norms governing youth behaviour and those of the Hong Kong society, where it is equally crowded and difficult for young people to find their own private space free from adult surveillance, it will be interesting to see whether similar or different patterns of youth SMS practices can be found in Hong Kong.

Another study in Taiwan (Yeh, 2004) consisted of in-depth interviews with 11 young people, 7 male, 4 female, aged 20-25 and their phone messages were also collected for textual analysis. It is found that SMS is used to negotiate subtle gender relations, especially among couples (e.g., after quarrelling, the other does not want to hear one's voice; avoiding embarrassment when making romantic advances or when saying 'no' to such advances). The informants also expressed that some messages are highly private and some are highly meaningful which they will keep.

Thus, both studies on East Asian youth text-messaging end on an optimistic note about the positive uses of SMS by young people for gaining freedom from surveillance by adults or for negotiating subtle gender relations. This is in line with Goggin's (2004) observation that young people took to text-messaging as a tactic of consolidating their shared culture, in distinction from the general culture dominated by their parents and other adults.

\section{Text Exchange as an Extension of Gift Exchange in the Economy of Intimacy and Desire}

Another important feature of SMS exchange practice is that it somewhat resembles the 'gift-exchange' practice in offline world (Johnsen, 2000; Pertierra, 2005; 2006). Social life in traditional society involves lots of exchanges, which concern both material and symbolic goods (Mauss, 1969). Some gifts may have an instrumental basis but some are valued by their symbolic significance. The exchange of gifts creates ties of dependence and reciprocity, and it ensures a kind of continued relationship between the sender and the receiver. Mauss (ibid.) argues that the act of gift giving is essentially the recognition of the moral basis of social life, which recognizes that people are entailed in one another in a relationship of mutual ontology. The sender and receiver are thus engaged in a moral relationship rather than an exclusively strategic one.

As Taylor and Harper (2003) point out in their study of youth usage of mobile phones, the practice of text messaging creates a level of reciprocity best understood as an extension of the gift-giving practice. Pertierra (2005) suggests that in text messaging, 
someone initiates the exchange and expects the other side to reciprocate, 'The text as gift is an important aspect of an economy of intimacy and desire' (2005:7). These communities of intimacy often involve person-to-person linkages, as each text requires a counter-text and these exchanges are seen as fundamental expressions of connectedness with each other. Hjorth (2005) uses the metaphor of 'postcard' to describe the symbolic function of text-messaging, as both of them include gestures of intimacy and hallmark clichés, and involve unspoken forms of obligation and reciprocity.

All the above studies were conducted overseas. Below we shall review studies on mobile phone and SMS practices in Hong Kong.

\section{Increasing Popularity of Text-messaging (SMS) in Hong Kong}

Hong Kong has been one of the places with the highest penetration of mobile phone service in the world for many years. From 1998 to 2003 the number of mobile service subscribers had increased 1.5 times. The number reached 7.19 million by the end of 2003, representing a penetration rate of 106\% (Source: www.info.gov.hk). Despite this high mobile phone penetration, SMS is not as widespread as in other economically developed Asian societies such as Singapore, the Philippines or South Korea. The TNS Asia Telecoms Index shows that only $43 \%$ of Hong Kong cellphone users use SMS and the average number of messages sent per user per month is only 23. This is perhaps due to the fact that Hong Kong was relatively late in introducing inter-operator SMS. There has been little promotion of SMS by the service providers in Hong Kong, either. Another possible reason is that mobile phone calling is relatively cheap in Hong Kong compared with other East Asian cities and so people do not need to use SMS to save on phone bills. One sociocultural reason might also be the fact that unlike other East Asian societies such as Japan (Ito and Daisuke, 2003) and Korea (Kim, 2002), talking loudly (especially by adults) over the mobile phone in Hong Kong public areas seems to be a common habit among many Hong Kong people and there does not seem to be great sociocultural pressure on Hong Kongers to switch their loud mobile phone talking mode to SMS mode so as not to disturb other people in public places such as the subway or the bus. SMS can thus be said to be a still largely under-developed area in Hong Kong.

However, Hong Kong youths are catching up fast in their SMS consumption. According to the statistics of Office of the Telecommunications Authority of Hong Kong, there were 116 millions of SMS messages sent in January 2005, as compared to 23 millions in December 2003, which marked an sharp increase of 388\% in two years (The Hong Kong Economics Journal, April 2005). 
However, there has only been one study on youth SMS practices in Hong Kong. Lin and Lo (2004) conducted a pilot study on the SMS practices of Hong Kong college students, and they found significant gendered differences in using SMS (e.g., significantly more females using SMS than males). Dating and social grooming with boyfriends/girlfriends also seem to be chief reasons for young people using SMS. As it was a quantitative study, it is difficult to dig into the deep social meanings of SMS practices. Thus it is in the spirit of preliminary, situated exploration that a pilot qualitative study on the SMS practices of Hong Kong college students was conducted between September 2005 and October 2005. The study aims at taking an initial look at what roles SMS may play in the everyday life of some young educated college students (particularly girls) in Hong Kong. Details of the study are presented in the next section.

\section{The Present Study}

The present study examines text-messaging cultures among young college girls in Hong Kong. We will examine the roles that SMS play in young college women's everyday life and discuss the implications of these emerging practices. We start off with two main research questions: First, as a new communication technology, how is the use of SMS similar with or different from other communicative devices (e.g. voice calls, e-mail, MSN, ICQ) in negotiating different kinds of social relations? Second, what are the symbolic meanings and emotional functions associated with the social practice of text-messaging?

The data collection methods consist of individual in-depth interviews and end-of-interview questionnaires. The interviews were conducted in the period between September and October in 2005. Using the snowballing method (Brown, 1994), twelve female informants (and three male informants; two of them are partners of two of the female informants) have been interviewed in the study (pseudonyms are used to protect the privacy of informants). All the interviews were audio-taped and transcribed. All quotes used in the paper were originally in Cantonese and were translated into English. As a pilot study, the small sample poses a major limitation on the study, but it does provide us with some initial insights on the emerging SMS practices among young college women in Hong Kong. The detailed accounts of our participants serve as valuable data for informing future studies. The background information of the informants is shown in Table 1.

\section{Table 1: Background Information of Informants}




\begin{tabular}{|c|c|c|c|c|}
\hline Name & $\begin{array}{l}\mathrm{Ge} \\
\text { nde } \\
\mathrm{r}\end{array}$ & Age & School/Faculty & $\begin{array}{l}\text { Years of } \\
\text { using } \\
\text { SMS }\end{array}$ \\
\hline 1. Bobo & $\mathrm{F}$ & 25 & English, Polytechnic University of Hong Kong & 3 years \\
\hline 2. Bulb & $\mathrm{F}$ & 19 & $\begin{array}{l}\text { Professional Accountancy, The Chinese } \\
\text { University of Hong Kong }\end{array}$ & $\begin{array}{l}3-4 \\
\text { years }\end{array}$ \\
\hline 3. Carrie & $\mathrm{F}$ & 23 & Business, University of Hong Kong & $\begin{array}{l}5-6 \\
\text { years }\end{array}$ \\
\hline 4. Eva & $\mathrm{F}$ & 19 & $\begin{array}{l}\text { Professional Accountancy, The Chinese } \\
\text { University of Hong Kong }\end{array}$ & 3 years \\
\hline 5. Katie & $\mathrm{F}$ & 19 & $\begin{array}{l}\text { Business Administration, Open University of } \\
\text { Hong Kong }\end{array}$ & 4 years \\
\hline 6. Kim & $\mathrm{F}$ & 21 & $\begin{array}{l}\text { Business Administration, Polytechnic University } \\
\text { of Hong Kong }\end{array}$ & 3 years \\
\hline 7. Kit & $\mathrm{F}$ & 21 & $\begin{array}{l}\text { Business Administration, University of Hong } \\
\text { Kong }\end{array}$ & $\begin{array}{l}5-6 \\
\text { years }\end{array}$ \\
\hline 8. Linda & $\mathrm{F}$ & 22 & English, Polytechnic University of Hong Kong & $\begin{array}{l}4-5 \\
\text { years }\end{array}$ \\
\hline 9. Mandy & $\mathrm{F}$ & 21 & $\begin{array}{l}\text { Professional Accountancy, The Chinese } \\
\text { University of Hong Kong }\end{array}$ & 2 years \\
\hline 10. Nancy & $\mathrm{F}$ & 21 & Language Studies, City University of Hong Kong & $\begin{array}{l}1-2 \\
\text { years }\end{array}$ \\
\hline 11. Suki & $\mathrm{F}$ & 20 & $\begin{array}{l}\text { Chinese Linguistic, City University of Hong } \\
\text { Kong }\end{array}$ & 2 years \\
\hline 12. Yuko & $\mathrm{F}$ & 23 & $\begin{array}{l}\text { Teaching English as the Second Language, City } \\
\text { University of Hong Kong }\end{array}$ & 4 years \\
\hline 13. Calvin & M & 21 & Mathematics, University of Hong Kong & 4 years \\
\hline 14. Man & M & 22 & English, Polytechnic University of Hong Kong & 1 year \\
\hline 15. Tom & M & 22 & $\begin{array}{l}\text { Teaching English as a Second Language, City } \\
\text { University of Hong Kong }\end{array}$ & 4 years \\
\hline
\end{tabular}

Findings and Analysis

The discussion in this paper will be divided into two main sections. The first section will explore the unique communicative features of SMS especially in affording a sense of intimacy for users in different kinds and stages of their social relationships. The second section will discuss the symbolic and emotional functions associated with text-messaging, in light of the literature on the role of gift exchange in strengthening social relationships. 


\section{SMS as a Resource in Achieving a Sense of Co-Presence and Intimacy by Young}

\section{College Students}

In this section, we will draw on the concept of 'co-presence' and 'intimacy' to discuss the role of SMS in different kinds and stages of social relationships among a group of young college women in the Hong Kong Chinese context.

SMS is compatible with youths' multi-tasking practices in their everyday lives:

Perceptual contact with friends without causing disturbance to their on-going tasks

One of the conditions for maintaining a sense of co-presence between friends is that of being easily available to each other. Our informants are asked to compare SMS with other communicative devices, and most of them say that SMS has some unique advantages which enable the users to be more 'readily available' to each other. For instance, Katie finds that SMS makes one easily accessible to her friends in all situations. 'Except when you have a computer in front of you at home, otherwise I will use SMS. Because it is convenient! (You always) bring with you the mobile phone, and can talk (send messages) everywhere.' Another informant, Linda, explains, 'In the case of MSN and ICQ, you need to wait till he/she is online, and then you have to be online too; it will have a time constraint.' A similar remark is made by Mandy when she says, 'I think SMS can make sure that he/she can receive (the message) immediately...It's different from MSN and ICQ, with which you can read the messages only when you are online.' This reveals one of the strengths of SMS convenience and easy access most of the time. This kind of communication can be carried out under most circumstances, provided that someone has his/her mobile phone with him/her, which allows youths to maintain perceptual contact with their friends at any place at any time.

While this type of perceptual contact is pervasive, it is less disturbing than other more direct means of communication such as phone calls. The use of telephone may cause disturbance to the receiver, who may be occupied with other tasks or activities at the moment. The use of SMS successfully avoids such kind of disturbance as it is compatible with the multi-tasking practices of youths in their everyday lives. SMS, unlike phone calls, do not require the undivided attention of the participants. One can be engaged in another on-going activity while doing texting. For instance, one of our informants, Nancy, points out, "Actually the reason for using SMS is, such as when you are traveling on a vehicle, suddenly think of someone, and you want to find him/her, but (you are) afraid that he/she is working, then you can just send him/her an SMS message, see if he/she is occupied.' Another informant, Bulb, prefers using SMS 
during the day-time, particularly in the morning. She explains the practice in this way: 'In the morning many people are occupied. (Some of them are) still sleeping, may be attending classes, or having a meeting.' Therefore, SMS is the best choice to contact people in the morning. In this sense, SMS resembles the qualities of phone calls, as it can reach the contact within a minute and responses can be very fast, but at the same time, it seems to pose minimum disturbance to others.

In addition to its easy availability and non-disturbing nature, our informants find that SMS affords a sense of closeness and intimacy. For instance, Bobo points out that SMS is more 'cordial and intimate' than MSN, 'Maybe SMS gives you a feeling that it is on the go. That are no constraints; you don't need to sit in front of the computer... and you can even do SMS messages in the washroom.' This provides them with a kind of virtual co-presence which form a strong binding force between the sender and the receiver. Ten out of fifteen informants believe that the use of SMS has made their relationship with the recipient 'a little bit closer', and three of them find the relationship to be 'a lot closer' with the use of SMS.

Friends are crucial to young people in contemporary society, and the use of SMS ensures their availability and accessibility. In our study, SMS is used by the informants to arrange social gatherings and to send greetings to friends during festivals. It shows that text-exchange enable young people to sustain and strengthen existing relationships. Many informants regard it as the best tool in keeping close and intimate relationships with their old friends whom they do not see too often due to physical distance (e.g. former classmates in secondary schools). For instance, Mandy emphasizes that SMS is particularly useful in bringing her and her ex-classmates close together. 'SMS can increase my contact with my secondary schoolmates. It is because (if you ask me) to call them by phone, it's really rare that (I will) pick up the phone and call them. But SMS can be used at any time and at any place, asking them: what are you doing, or when can you come out and play, just like that. This can make us closer.' SMS communicative practices thus provide them with a sense of intimacy and togetherness with their old friends, whom they cannot see regularly.

\section{SMS as a resources in initiating new relationships}

In addition to maintaining existing social relations, SMS also provides a channel for users to develop new friendship with newly met people, to know one another bit by bit in the textual world. Ling and Yittri (2002) suggest that SMS helps one to explore potential new friends, and the friendship is situated in a more careful and controllable context. Sung and Yeung (2005) also find that Mainland college students only make 
phone calls to classmates and lovers frequently, but in case of SMS, they will have a wider range of targets. Many of our informants agree that SMS facilitates more open communication and increases their opportunities of contacting new, unfamiliar friends, including those who may be further developed into romantic partners. It encourages new contacts and enlarges one's social network by providing a form of pervasive but non-disturbing contact. Most important of all, it is particularly useful for girls to employ tactics in initiating a new, intimate relationship.

The exchange of text resembles online chat in turn taking and discourse structure (Kasesniemi and Rautianien, 2002), which is different from direct face-to-face or voice-to-voice interaction. It affords a form of intimacy but also a 'safe' distance between the users. On top of a sense of co-presence, it offers both time and space for buffering. It is believed that asynchronous text-based communication allows users time to select, craft out, and edit the personality they want to present in their messages. In our study, some informants appreciate the asynchronous text-based nature of SMS, which can be utilized as a powerful tool for girls. For instance, Linda explains this with an example of approaching a stranger, 'If you have just known someone, you do not know what to say to him on phone. If you send him a text message, you can just type one sentence... it seems that you do not need to respond immediately in front of a stranger...you do not know what to say, and you are afraid of dead air. But when you write a text, there are no such problems.'

In fact, SMS can help one to initiate ambivalent relationships, and some of them can be further developed into offline romance relationships. Ellwood-Clayton (2003) finds that some Filipinos are restructuring amorous lived relationships and creating virtual ones through text communication. In this study, SMS seems to provide a space for further developing emerging amorous feelings and romance, and it is found to instill personal bravery among its users. One of the female informants, Suki, believes that SMS marks the starting point of a close relationship, as it allows her to understand this male friend more deeply in a non-embarrassing context. She illustrates it with her own experience, 'It really made us closer! It is because he is not so talkative, but when he sends me SMS, (I discover that) though he usually speaks very little, he can actually express a lot in SMS. Then I become more familiar with him. And sometimes when (we) cannot talk in a face-to-face context, (we) can talk a lot in SMS.'

In particular, women are encouraged to speak out their feelings and take more initiative in the textual world, which seems to subvert the traditional gender roles in courtship among young Chinese (e.g., traditionally, Chinese women are not supposed to take the initiative to court a member of the opposite sex). They tend to develop 
intimate relationship more easily through this pervasive but indirect contact. Some of our female informants find that they can be more active and expressive when they chat with male friends in SMS. As a result, they consider it to be the 'best communicative means' in starting a relationship. One of our informants, Eva, who have many 'male SMS friends', says, 'it's so convenient, just type a few words and you can date him out... if he is a boy, it is a bit rude to phone him! So (I) prefer using SMS with boys...calling is too... it is too active. (SMS) seems to be less formal.' She suggests using SMS at the initial stage of a relationship, to test whether two people can get together. In case they cannot communicate well in the textual world, it is easier and more natural for them to terminate the relationship as soon as possible.

Due to the absence of visual and vocal signals, girls are encouraged to express their words of heart more bravely, particularly in the initiate stages of courtship. Another female informant, Nancy, describes SMS as a mixed from of 'passive' and 'active' communication styles, which is particularly suitable for girls to confess their love to boys. She says, 'this method is active and yet passive. You can ignore his reaction (after receiving your message)...no need to care whether he replies to you or not, but you can let him know what you think.' This shows that SMS can be used as a 'tactic', as a kind of 'strategy', especially by Chinese girls, to develop a closer relationship with a male friend. The users can explore their common interests and get to know one another better at the early stage of a relationship. Though the relationship may be confined to the textual world at the beginning, many of them do extend it to the off-line world after a period of time (e.g. Suki and Eva). This reveals that SMS enables them to negotiate relationships with males in an 'intimate' but also 'distanced' and safe space.

\section{$\underline{\text { SMS as an ideal space for communicating with lovers }}$}

Many studies have shown that the cell phone provides users with a site to explore their desires, as compared to traditional face-to-face communication (Ellwood-Clayton 2003; Kasesniemi and Rauntianen 2002; Pertierra et al, 2002). In our study, it is found that SMS provides a site for sustaining two types of romance relationship with such a medium of expression. The first type is the ambivalent relation which is still emerging in the early or 'underground' stage. Another type is that of romantic partners. As revealed by some of our informants, SMS allows new forms of intimacy between lovers. It provides a platform for transmission of both 'unsayable' and ordinary topics, and also exchanging some "poetic" quotes that people seldom mention in other situations. As suggested by Pertierra (2006), the requirement for privacy is crucial for many aspects of modernity. Since mobile 
phones are very personal belongings, text exchange thus provides a sense of privacy for the sender and receiver, and it allows them to express their inner feelings in this private space more easily.

Some informants considered SMS to be particularly helpful for Chinese people, since they say we are less willing to express our inner worlds directly by speech. For instance, Nancy says, 'I think SMS allows you to write from your heart, not speak from your heart...Sometimes may be Chinese, or Eastern people are like this. I find something difficult to speak out, cannot be spoken, then (I will) use, I used letters before, and now use these three tools (SMS, MSN and ICQ).' Yuko believes that Chinese people need some channels to reveal their inner world, and SMS provides them with this opportunity. 'It is because I am a Chinese, I'm not like the Westerners, (they) can say "I love you" naturally. Chinese are relatively more reserved...those real feelings in your heart, (you will wait till) a particular situation, a particular moment, then you will finally speak it out. But these situations may not be there all the time, so you can make use of text-messaging.'

Haig (2002) suggests that SMS provides privacy, as the conversations remain private even in public locations, which makes it totally different from making direct phone calls. As a result, people may tend to reveal more about their emotional selves in the textual space. One of the illustrative examples of the private, 'unspoken' topics is sweet words and honeyed phrases among lovers. The 'sweet talk' between couples reveals a kind of text-based, virtual intimacy that is brought about and facilitated by text-exchange. Linda says, 'There is the feeling that it can be sweeter in SMS. Just like you will call him honey and darling, but you will not say it by your mouth. You can just type it out.' Another informant, Bobo, makes a similar remark, as she will say something 'very sweet' in SMS messages. She used to call her partner 'xiang gong'(相公, a formal Chinese term to address one's husband in the ancient times; e.g., as found in Chinese historical dramas), and her boyfriend used to call her 'niang zi' (娘子, a formal Chinese term to address one's wife in the ancient times; e.g., as found in Chinese historical dramas).

It is interesting to find that both girls and boys in our study find it easier to 'speak out' their feelings and exchange sweet words with their partners through text-messaging. For instance, one of our male informants, Man, has never thought of sending SMS messages before he met his present girlfriend, but now he finds it extremely useful in sustaining a close relationship. He admits that SMS provides him with an alternative space for adopting a different communicative style. This seems to bring about some 
new possibilities for boys to go beyond the traditional patterns of expression, allowing them to communicate with girls using a shared language and converging style. In short, it is consistent with Ellwood-Clayton (2006)'s saying that mobile phones provide young people with an avenue to express their desires, and to deepen intimate relationships. It is also particularly useful for Chinese people, who are perceived as more 'restrained' and 'conservative' by our informants, and provides them with a safe textual space to nurture and sustains romantic love, and creates a sense of excitement and intimacy between lovers, which they might find difficult to express face to face or in speech.

\section{Symbolic and Emotional Functions of Text as a Gift}

According to our informants, around two-third of the messages are used for friendship maintenance, romantic and social functions associated with intimate and relational concerns, and only one-third of them are used for practical information exchange. Thus texts are often considered as performing social, emotional and sentimental functions, rather than instrumental ones. It seems that text-messaging plays an important role in enabling its users to share feelings of intimacy in a gift exchange process. In the following section, we shall explore the functions achieved by this gift-exchange practice through SMS, which go beyond the moral obligation of reciprocity, but also includes the personal and sentimental functions of the text as a gift.

\section{$\underline{\text { Confirmation of a close relationship }}$}

As shown in the above, SMS provides a way of maintaining perpetual social contact and sense of intimacy, which contributes to the maintenance of different forms of social relations. In our study, all of our female informants participate in the practice of sending season's greetings and birthday greetings to their friends, partners, and family members. It seems that such kinds of greetings fulfill the care-taker and expressive roles of girls expected in some cultures. In some cultures, the everyday tasks of mothering, like the routine care of home and children, are taken to be the natural expressions of femininity (Coltrane, 2004); expressing tender feelings, being gentle are also considered to be ideal qualities for women (Cancian, 2004). In particular, our own socialization experiences told us that Chinese women are taught to be more considerate and caring, and are expected to be more attentive and more willing to show concern for others. It is believed that more females than males tend to send season's greetings and birthday greetings (e.g., Christmas cards, birthday cards), and traditionally more females than males tend to be willing to spend more efforts and time in keeping up good relationships by social grooming and reciprocating 
communication and gifts although this kind of traditional gender role relationships may be changing fast in the modern society..

This kind of greetings resembles the role of gifting during special seasons and festivals. In expressive messages, texting can be a form of intimate sharing between users. Texting is a form of technology allowing the meaning of speech to be preserved and transmitted, while speech is limited to face-to-face situations or preserved in memory. As mentioned by our informants, SMS somewhat resembles the role of letter-writing (also a kind of reciprocal relationship), but with much more advanced technological features than letters. Linda's remark is highly illustrative: 'This is a new way to communicate. When you want to chat with someone, and you don't want to do it directly, you may need to use ICQ or MSN, that is writing online, since writing letters is no longer popular...If you want to communicate through writing before, (you) need to do it at home. That is (you need) a place where there is a computer. But now when you want to communicate through writing, (you) can do it anytime everywhere. It seems that there is one more method to communicate.' As mentioned in the previous section, they believe that Chinese people prefer writing one's mind rather than speaking it out directly. Therefore, this modern format of 'letter-writing' has become a type of social interaction in which the sender and receiver share a common experience, and they are being engaged in a reciprocal relationship.

It seems that texting is now a key tool in sustaining emotional lives of young people (Vincent, 2003), and many informants consider SMS as an essential part of their social life. Pertierra (2006) considers this expression of gift exchange as laying the basis for friendship; and in the practice of text-messaging, receiving messages is a confirmation of one's membership in the group (Ling and Yttri, 2002). As illustrated by some of our informants, it acts as an indicator of close relationship or one's ability to be likable and liked. For instance, Kit explains the indicator function like this, 'If the frequency of (sending and receiving) SMS is high, you will feel that the relationship between you two is closer! You will think that you have occupied the time of that person, or occupy his/her energy; so I will feel closer (with him/her)!' Another informant, Kim, said that she will be very disappointed if she doesn't receive greetings on her birthday or other special festivals (e.g., Christmas, New Year). 'I will turn on the phone very early in the morning, see how many messages I will receive...if (I) cannot receive any, (I) will be very unhappy.'

In fact, this confirmation of close relationship requires some effort in crafting a message. The kind of 'gift' exchanged should symbolize the specific relationship 
between the sender and the receiver to make the relationship more private and intimate. It should be noted that many informants emphasize originality and creativity in composing text messages (particularly birthday and season's greetings). In our study, sending messages to multiple recipients is not a very popular practice among our participants, as many of them criticized multiple-recipient messages as 'too insincere' and 'lacking in originality'. Carrie is one of the informants who oppose sending multiple-recipient messages for personal greetings; she claims that she never writes multiple-recipient greeting messages. 'The whole thing is totally lacking of sincerity! In case of greetings, at least add the name of the other side, or having something, saying something just between you and me.'

Another informant, Kimmy, is very sensitive in choosing appropriate words in text messages, and she usually sends season's greetings to her friends separately, instead of utilizing the 'multiple-recipient' function. She cites Valentine's message as an example, as she is sensitive enough to craft different kinds of messages to those girls 'with a boyfriend' and those 'without a boyfriend'. Another informant, Eva, is interested in writing letters, and she emphasizes the uniqueness in composing season's greetings. 'I will (write something) specific to that person, won't repeat (the same message)...or write something related to the relationship between you two.' As they practice how to write a passage to suit specific needs, they are actually recognizing and being sensitive to a close relationship with individual receivers. Thus the act of sending 'personal' messages (at least perceived to be personal) possesses a kind of symbolic significance in confirming one's important position, and the frequency of text-exchange is highly related to the popularity of a person in a social circle, as perceived by our young informants.

\section{$\underline{\text { SMS as a gift with multiple functions at different times }}$}

Apart from the function of establishing reciprocal relationships, one important feature of gift is that it can be kept for future remembrance. In this study, all of our informants report the practice of saving messages (particularly sweet words from partners, encouragement from good friends, and also season's greetings) in their original forms and preserve the embodied memories. This is regarded as a common practice in youth social networks. Most of them claim that they will not delete the messages 'unless the memory is full' (i.e., exceeding the maximum storage limit of mobile phones). For example, Suki will keep all encouragement messages and greetings from friends, the sweet words of her ex-boyfriend and important words of important persons'. Another informant, Kit, recognizes and values the effort put in by the sender, so she also likes keeping messages in her mobile phone, "(Others) spend 
time on typing a message for you; it's a kind of regard, I think." A male informant, Tom, will even type the messages into a word file, in case he needs to delete the original texts stored in the mobile phone due to limited space.

Apart from keeping these messages, they will also re-read them at different times and for different purposes. The SMS texts actually act as 'handy-letters' with symbolic and sentimental value, as the mobile phones are small in size to carry, and over hundreds of messages can be kept. This enables them to enjoy the pleasant and meaningful memories embodied in the text messages at any place at any time. The most commonly cited function is to 'kill time', especially when they are on the street. As mentioned in the previous section, mobile phones are easily available and accessible, they can be easily obtained and used when people are in need. Some of our informants consider re-reading messages as the 'best activity' when they are 'waiting for someone', 'hanging around on the street', 'traveling on a bus', and even 'failing to fall asleep'. This is similar to the practice of reading a novel, which acts as a kind of leisure activity, but this time the content is highly personal and sentimental.

It is generally believed that text-messaging enables more private emotional exchange and communication among youths (Sung and Yeung, 2005). Haig (2002) suggests that people tend to reveal more about their emotional selves in the text, as the textual world is a highly personal space with privacy and open communication. As indicated by some of our informants, those expressive messages perform a very crucial emotional function not just at the time of exchanging the text, but also at the time they re-read the messages when in need. Some of our informants use them to encourage themselves when feeling sad and lonely, as the messages give them a warm feeling and a sense of assurance. For example, Suki likes to read the messages from good friends whenever she feels upset, and they can always cheer her up. 'Sometimes it's very encouraging and inspiring when (I) read (them)...Sometimes (I am) unhappy, and reading the messages is very encouraging, giving me some strength to face the challenges.' Another informant, Kim, finds it useful in increasing her self-confidence, 'I read them when I want to be touched, as I want to find some support and recognition'.

Another important function is to recapture the wonderful memories that have past away. For instance, Nancy has lost connection with a very intimate friend recently, but she still keeps his messages in her mobile phone. Whenever she thinks of him, she will re-read those messages and feels a bit more relieved. Another illustrative example is Calvin, a male informant, who points out that SMS allows people to 'relive the 
warm moments' at any time, as 'mobile phone is a very personal thing'. He recalls his own experience, 'During the night, you cannot find him/her at any time, but (you) can read (the message) again, the whole thing is so sweet.' A similar function is achieved when they cannot reach a person immediately, so re-reading their words give them some comfort and compensation. Carrie, who is a 'third-party' in a triangular relationship, often re-reads the messages sent by her boyfriend: 'sometimes it's not convenient to call that person, but I miss him, so (I'll) read his messages.' All these practices reveal the emotional functions associated with this electronic textual 'gift', and this gift can serve different purposes at different times. Thus SMS seems to be expanding these young people's emotional resources to cope with life's loneliness and ups and downs.

\section{Conclusion}

As indicated in our findings, young college girls seem to find SMS very useful in providing a sense of intimacy, gaining friends by nurturing new relationships and strengthening previously established friendships. In modern day society, everyone is tied up with busy work schedules, and people who used to be good friends are separated by rapid and frequent dislocations. It might be difficult for them to keep in touch with one another, and many social relations have become loosened or even lost. New mobile communication technologies (including SMS) thus allow them to keep in touch with friends and loved ones in a society with frequent relocations, and also experimenting close and amorous relationships among youths who place great importance on relationship-building. In particular, text-exchange somewhat resembles the role of gift exchange, and the sharing of expressive and sentimental messages act as confirmation of a close relationship. As shown by our informants, text-messaging's unique functions in nurturing and sustaining social and emotional bonds is most appealing to them. In the following sections, we shall elaborate these points.

\section{Intimate Relationships Associated with a New Form of Technology}

Text-messaging seems to open up the possibility of openness, as it encourages new contacts and enlarges one's social networks. It is similar to the idea that SMS resembles a virtual cafeteria or marketplace where people can meet each other (Puro, 2002; Vincent, 2003). And this virtual cafeteria is carried in one's pocket and can be accessed anytime anywhere. As shown in our findings, young Hong Kong Chinese college girls find SMS very useful in gaining friends by encouraging them to take the initiative to start new relationships while sustaining previously established friendships. SMS encourages these girls to explore close and intimate relationships and to express their feelings to members of the opposite sex more uninhibitedly. In particular, 
expressive messages act as confirmation of a relationship, a type of social interaction in which the sender and receiver share a common experience, and develop a converging communicative style, especially between men and women. They develop a common narrative and history (Ling and Yittri, 2002). SMS might thus serve as a catalyst in helping men and women to communicate less uninhibitedly and to develop and adopt converging communicative styles (i.e., crossing traditional gender role boundaries; e.g., both men and women can confess their love less uninhibitedly; women can be encouraged to express their feelings more openly).

In short, SMS helps maintain social relations in modern society, and affords resources to achieve a sense of co-presence and intimacy with both existing friends and newly met people, while it avoids having to deal with the fluster and embarrassment of a face-to-face interaction or the intrusive disturbance of a phone call. In some cultures, it seems that females are often socialized to be more considerate and caring, or more eager in building a good relationship with others (Tannen, 1996). In our study, young girls express their preference to express their caring feelings and send greetings to others (including partners and friends) using SMS. They also find it less disturbing and more considerate by reaching others through text-messaging. This fits the image of the care-taker, a role that is often expected to be performed by a female in some cultures (and the socialization experiences of the authors in a Chinese society speak to this observation). In this aspect, the new mobile communication technology seems to have inserted itself into existing sociality and discursive practices without initiating any radical transformation of young women's ways of life. SMS thus seems to be providing one more effective tool to girls who have been doing it with other (perhaps less effective) means of communication already. Our female informants emphasize that friends are very important for them, and they will feel lost or depressed if they do not receive SMS from their friends for a few days. Many of them admit that they have already become addicted (to SMS) and take it as a proof of friendship, or even a measure of one's popularity.

\section{Converging Communicative Styles for Both Boys and Girls in Self-Expression}

It seems that SMS has not radically changed the existing gendered pattern of sociality practices, at least speaking from the preliminary data of our pilot study. However, negotiation of gender roles and practices that are slightly different from traditional norms seems to be actually taking place at the same time. As shown by our informants, there is a possibility of developing ambivalent/romantic relationship through SMS, and girls are encouraged to take initiative in this textual world. In the old days, women were taught to act like not liking someone in terms of courtship, but 
modern day women are no longer as inhibited to remain passive in the game of courtship (Ellwood-Clayton, 2003). Modern women are now exploring new roles and identities made viable by SMS, where they can shift and play with new roles, being more active and expressive, and even subverting traditional gender roles by initiating a romantic relation. In our study, some female informants try to date their male friends out, or say some sweet and honeyed phrases in the SMS messages, while they may not feel comfortable to do these with other communicative media. This shows that despite conforming to certain existing social norms governing gender roles and practices, SMS also enables them not to adhere to traditional norms of gender conduct sometimes. This may increase the agency of women, and may gradually change traditional norms governing gender relations in some cases.

On the other hand, it seems that SMS can also bring about change and breakthroughs for young men, as our male informants (though limited in the sample size) report exchanging sweet words and inner feelings with friends (particularly girlfriends and friends of the opposite sex) more readily in the SMS textual world. Men and women are traditionally believed to have different ways of expressing themselves in most, if not all, communication channels (Tannen, 1996). The expression of tender feelings is considered to be ideal qualities for women and not for men (Tannen, ibid.). In particular, the feminized definition of love and feelings seems to dominate both contemporary scholarship and public discourses on love and romance. Men are expected to be independent, unemotional and not so deeply involved in love relations. However, as shown by our male informants, SMS actually opens up a wide discursive space for both private expression (of sweet words) and daily frequent conversations (about what happens during the day). Nevertheless, we have just interviewed three male informants in our study, and the sample may not be representative. More informants should be recruited in future studies to look into the issues.

To conclude, it seems then that this new mobile communication technology is useful for modern young women to sustain different types of social relationships (e.g. relationship between family members, friends and romantic partners) in a modern society with frequent relocations of people, and it may also interact with existing socio-cultural and discursive practices to produce gradual change in the traditional gendered patterns of communicative practices. And it might be possible that this new mobile communication technology can increase the agency of young modern Chinese women, at least in encouraging them to take more initiative in self-expression and relationship-building (particularly in starting and sustaining romantic relationships). 
This transformation of ways of being (e.g., sociality and discursive practices, gendered communication practices) may be gradual and may emerge invisibly as more and more young people (including males) become SMS users for a broader ranger of purposes. Further research studies should study both female and male informants, in the forms of ethnographic studies, communication diaries, and focus group interviews, in order to study the different cultural and social practices of male and female users.

\section{References}

Allison, R. (Jan 22, 2001). Phone Text Chat "Harms Literacy". The Guardian, pp.7.

Apple Daily (Sept 20, 2004) CSL Estimates that SMS Promotion will Become Popular, B03.

Cancian, F. M. (2004) The Feminization of Love, in M. S. Kimmel \& A. Aronson (eds.), The Gendered Society Reader (second edition). New York \& Oxford: Oxford University Press.

Coltrane, S. (2004) Household Labor and the Routine Production of Gender, in M. S. Kimmel \& A. Aronson (eds.), The Gendered Society Reader (second edition). New York \& Oxford: Oxford University Press.

Cooper, G. (2001). The Mutable Mobile: Social Theory in the Wireless World, in B. Brown, N. Green, \& R. Harper (eds.), Wireless world: Social Aspects and Interactional Aspects of the Mobile Age. London: Springer.

Crabtree, J., et al. (2002) Reality IT-Technology and Everyday Life. London: i Society.

Ellwood-Clayton, B. (2003) Virtual Strangers: Young Love and Texting in the Filipino Archipelago of Cyberspace, in K. Nyiri (ed.), Communications in the $21^{\text {st }}$ Century. Mobile Democracy: Essays on Society, Self and Politics. Hungary: Passagen Verlag.

Ellwood-Clayton, B. (2006) All We Need is Love-and a Mobile phone: Texting in the Philippines. Paper presented at the International Conference on Cultural Space and Public Sphere in Asia, 15-16 March 2006, Seoul, South Korea.

Galan Rodriguez, Carmen (2001). SMS? A new language model ? Espanol Actual, 76, 93-103.

Gergen, K. J. (2002). The Challenge of Absent Presence, in J. E. Katz and M. Aakhus (eds.), Perpetual Contact: Mobile Communication, Private Talk, Public Performance. Cambridge: Cambridge University Press.

Goggin, G. Mobile text, (2004). M/C: A Journal of Media and Culture, 7, http://www.media-culture.org.au/0401/03-goggin.html. 
Goffman, E. (1959). The Presentation of Self in Everyday Life. Garden City, New York: Doubleday.

Goggin, G. (2006) Txt Msg: The Rise and Rise of Messaging Culture, in Cell Phone Culture: Mobile Technology in Everyday Life. London and New York: Routledge.

Grinter, R. and Eldridge, M. (2001) Y Do Tngrs Luv 2 Txt Msg?, in W. Prinz et al. (ed), Proceedings of the Seventh European Conference on Computer-Supported Cooperative Work ECSCW 01. Dordecht, Netherlands: Kluwer.

Haig, M. (2002) Mobile Marketing: The Message Revolution: 'A cracking insight into how to really get personal with your customers'. U.S.: Kogan Page.

Hard af Segerstad, Y. (2003). Use and Adaptation of Written Language to the Conditions of Computer-Mediated Communication. Unpublished doctoral dissertation, University of Goteborgs, Sweden.

Hjorth, L. (2005) Locating Mobility: Practices of co-presence and the persistence of the postal metaphor in SMS/ MMS mobile phone customization in Melbourne, Fibreculture Journal 6, http://journal.fibreculture.org/issue6

Ito, M. (2002) Mobiles and the appropriation of place, Receiver Magazine, 8, http://www.receiver.vodafone.com/

Ito, M. and Daisuke, O. (2003). Mobile Phones, Japanese Youth, and the Re-Placement of Social Contact. Paper presented at the conference: 'Front Stage-Back Stage: Mobile Communication and the Renegotiation of the Social Sphere', June 22-24, 2003, Grimstad, Norway.

Ito, M. and Okabe, B. (2005) Technosocial Situations, in M. Ito, D. Okabe and M. Matsuda (eds), Personal, Portable, Pedestrian: Mobile Phones in Japanese Life. Cambridge, MA: MIT Press.

Johnsen, T. E. (2000) Ring Meg! En Studie Av Ungdom Og Mobiltelefoni. Department of Socioplogy, University of Oslo.

Kasesniemi, E. L. and Rauntianen, P. (2002) Mobile Culture of Children and Teenagers in Finland, in J. Katz and M. Aakhus (eds.), Perpetual Contact: Mobile Communication, Private Talk, Public Performance. Cambridge: Cambridge University Press.

Katz, J. E. and Aakhus, M. A. (2002). Conclusion: Making Meaning of Mobiles-A Theory of Apparatgeist, in J. E. Katz \& M. A. Aakhus (eds.), Perpetual Contact: Mobile Communication, Private Talk, Public Performance. Cambridge: Cambridge University Press.

Kim, S. D. (2002). Korea: Personal meanings, in J. E. Katz \& M. A. Aakhus (eds.), Perpetual Contact: Mobile Communication, Private Talk, Public Performance (63-79). Cambridge: Cambridge University Press. 
Lin, A. and Lo, J. (2004). New Youth Digital Literacies and Mobile Connectivity: Text-messaging among Hong Kong College Students. Paper presented at the International Conference on Mobile Communication and Social Change, 18-19 October 2004, Seoul, South Korea.

Ling, R. (2004) The Mobile Connection: The Cell Phone's Impact on Society. San Francisco, CA: Morgan Kaufmann Publisher.

Ling, R. (2000) Direct and Mediated Interaction in the Maintenance of Social Relationships, in A. Sloane and F. V. Rijn (eds.), Home Informatics and Telematics: Information, Technology and Society. Boston: Kluwer.

Ling, R. and Yttri, B. (2002) Hyper-Coordination via Mobile Phones in Norway, in James E. Katz, and Mark A. Aakhus (eds.) Perpetual contact: Mobile Communication, Private Talk, Public Performance. Cambridge: Cambridge University Press.

Lobet-Maris, C. (2003). Mobile Phone Tribes: Youth and Social Identity, in James E. Katz, and Mark A. Aakhus (eds.) Perpetual contact: Mobile Communication, Private Talk, Public Performance. Cambridge: Cambridge University Press.

Longman English Dictionary (1988) Longman Group UK Limited.

Mauss, M. (1969) The Gift. I. Cunnison (trans). London: Cohen and West.

Nyiri, K. (ed.) (2003) Communications in the $21^{\text {st }}$ Century. Mobile Democracy: Essays on Society, Self and Politics. Hungary: Passagen Verlag.

Pertierra, R. et al. (2002) Txt-ing-Selves: Mobile phones and Philippe Modernity Manila: De La Salle University Press.

Pertierra, R. (2006) The Transformative Capacities of Mobile Phones and the Internet-a Philippine Example. Paper presented at the International Conference on Cultural Space and Public Sphere in Asia, 15-16 March 2006, Seoul, South Korea.

Pertierra, R. (2005) The Gift of the Text. Asian Digital Cultures Conference. Paper presented at the Asian Digital Cultures Conference, 28-29 July 2005, Institute of Ethnology, Academia Sinica.

Pietrini, D. (2001). The SMS and the Triumph of Informality and Ludic Writing. Italienisch, 46, 92-101.

Prøitz, L. (2005) Cute Boys or Game Boys? The Embodiment of Femininity and Masculinity in Young Norwegians' Text Message Love-Projects, Fibreculture Journal 6, http://journal.fibreculture.org/issue6

Puro, F. P. (2002) Finland: A Mobile Culture, in James E. Katz, \& Mark A. Aakhus (eds.), Perpetual Contact: Mobile Communication, Private Talk, Public Performance. Cambridge: Cambridge University Press. 
Smoreda, Z. and Thomas, F. (2001) Social Networks and Residential ICT Adoption and Use, in EURESCOM Summit 20013 G Technologies and Applications (Nov 15). Heidelberg: EURESCOM.

Sung, S. and Yeung, S. W. (2005) Self Orientation of College Students and Consumption of Cell phones, Journal of Social Theory, 8 (1), 3-19.

Tannen, D. (1996). Gender and Discourse. New York: Oxford University Press.

Taylor, A. and Harper, R. (2003) Age-old Practices in the "new World": A Study of Gift-giving between Teenage Mobile Phone Users, in Changing Our World, Changing Ourselves (proceedings of the SIGCHI Conference on Human Factors in Computing Systems, Minneapolis, 2003): 439-46.

Tweedle, Mark (Oct 1, 2003). Correct Spelling. The Times, p.17.

The Hong Kong Economics Journal (April 5, 2004) A Flood of SMS, A15.

Vincent, J. (2003) Emotion and Mobile Phones, in K. Niyiri. (ed), Communications in the $21^{\text {st }}$ Century. Mobile Democracy: Essays on Society, Selfa and Politics. Hungary: Passagen Verlag.

Williams, R. (1983). Mobile Privatization. Reprinted in P. Gay, S. Hall, L. Janes, H. Mackay, \& K. Negus (1997), Doing Cultural Studies: The Story of the Sony Walkman. London: Sage.

Wilson, D. (Sep 23, 2003). Texting Threatens the Correct Use of English, South China Morning Post, p.5.

Yeh, M-J. (2004) A Preliminary Study on SMS Use of Youth Tribes. Information Society Research 6: 235-282. [Original in Chinese]

Yoon, K. (2003) Retraditionalizing the mobile: Young people's sociality and mobile phone use in Seoul, South Korea, European Journal of Cultural Studies 6 (3), 327-343. 